\title{
PIPERACILLIN ESTIMATION BY ION-ASSOCIATIVE COMPLEX FORMATION
}

\section{GIRI PRASAD GORUMUTCHU ${ }^{1}$, VENKATA NADH RATNAKARAM ${ }^{2 *}$, KIRAN KUMAR KATARI ${ }^{3}$}

${ }^{1}$ Department of Chemistry, Acharya Nagarjuna University, Nagarjuna Naga, Andhra Pradesh, India. ${ }^{2}$ Department of Chemistry, GITAM University, Bengaluru, Karnataka, India. ${ }^{3}$ Department of Chemistry, Kakarparthi Bhavanarayana College, Vijayawada, Andhra Pradesh, India. Email: doctornadh@yahoo.co.in

Received: 23 October 2018, Revised and Accepted: 23 November 2018

ABSTRACT

Objective: The objective of the study was to develop a simple, validated, and affordable visible spectrophotometric method for determination of piperacillin (PIP) present in bulk and powder for injection formulation.

Methods: In the present method, cobalt thiocyanate (CTC) was used as a chromogenic reagent where it forms 2:1 ion pair complex at pH 2 with PIP which is having secondary and tertiary amine groups.

Results: The formed bluish-green colored ion pair between PIP and CTC is quantitatively extractable into nitrobenzene with an absorption maximum of $665 \mathrm{~nm}$. Regression analysis ( $\mathrm{r}=0.9996)$ shows that the plotted calibration curve exhibits good linearity in the studied range of concentration (3-18 $\mu \mathrm{g} / \mathrm{mL})$. Low values of relative standard deviation $(<2 \%)$ were observed indicating that the proposed method is reproducible, accurate, and precise.

Conclusions: As per the existing guidelines of ICH (international council for harmonization of technical requirements for pharmaceuticals for human use), various parameters of the proposed method were tested for validation and can be used method of choice for routine analysis in industrial quality control laboratories, especially in developing countries.

Keywords: Validation, Piperacillin, Cobalt thiocyanate, Ion pair extraction, Assay.

(C) 2019 The Authors. Published by Innovare Academic Sciences Pvt Ltd. This is an open access article under the CC BY license (http://creativecommons. org/licenses/by/4. 0/) DOI: http://dx.doi.org/10.22159/ajpcr.2019.v12i3.29289

\section{INTRODUCTION}

Piperacillin (PIP) is a semisynthetic antibiotic used for the treatment of serious, hospital-acquired infections, and polymicrobial infections [1,2]. Its chemical structure is shown in Fig. 1. Until date, very few analytical methods were reported for the determination of the drug individually or in combination with other drugs using techniques such as LCMS/MS [3,4], HPLC MS/MS [5], HPLC [6-12], and ultraviolet (UV) [13-16]. However, no analytical method is available in literature for the determination of PIP using visible spectrophotometry. Hence, an extractive ion pair complex formation method is proposed in the present study for determination of PIP by visible spectrophotometry.

\section{MATERIALS AND METHODS}

All chemicals used were of analytical reagent grade, and distilled water was used throughout the investigation. TECHOMP (UV 2310) double beam UV-visible spectrophotometer with HITACHI software version 2.0 was used to measure the absorbance. Quartz cuvettes $(10 \mathrm{~mm}$ path length) were used for the analysis. Shimadzu AUX-220 balance and Elico LI-120 digital $\mathrm{pH}$ meter were used to weigh the samples and to measure $\mathrm{pH}$, respectively. Spectroscopic measurements were conducted at room temperature $\left(25 \pm 5^{\circ} \mathrm{C}\right)$.

\section{Preparation of reagents}

Cobalt thiocyanate solution (CTC solution)

It was prepared by dissolving $7.25 \mathrm{~g}$ of cobalt nitrate and $3.89 \mathrm{~g}$ of ammonium thiocyanate in $100 \mathrm{~mL}$ of distilled water.

\section{pH 2 buffer solution}

It was prepared by mixing $306 \mathrm{~mL}$ of $0.1 \mathrm{M}$ tris sodium citrate with $694 \mathrm{~mL}$ of $0.1 \mathrm{M} \mathrm{HCl}$ and the $\mathrm{pH}$ adjusted to 2 [17].
Standard PIP solution

It was prepared by accurately weighing about $100 \mathrm{mg}$ of in $100 \mathrm{~mL}$ volumetric flasks separately. Then, the drugs were dissolved with $25 \mathrm{~mL}$ of methanol and sonicated to dissolve it completely and made up to the mark with the same solvent. The contents were mixed well and filtered through Ultipor ${ }^{\circledR}$ Nylon 6,6 membrane. Standard stock solution concentration of $1000 \mu \mathrm{g} / \mathrm{mL}$ was obtained.

\section{RESULTS AND DISCUSSION}

\section{Absorption spectrum of colored complex}

A characteristic absorption maximum was observed at $665 \mathrm{~nm}$ for the developed chromophore in determination of PIP by visible spectrophotometry (Fig. 2).

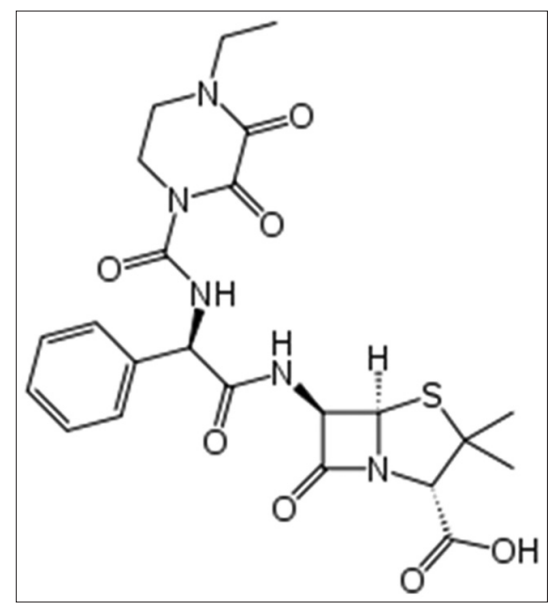

Fig. 1: Chemical structures of piperacillin 


\section{Optimization of reactions conditions}

The optimum reaction conditions for the complex formation were established. While maintaining the constant volume of aqueous layer $(20 \mathrm{~mL})$, volume of CTC solution was increased. Optimum CTC volume was found to be $5.0 \mathrm{~mL}$ (Fig. 3) which may be excess than the stoichiometric requirement in view of two reasons. CTC itself undergoes dissociation in aqueous medium, and excess CTC volume helps the stabilization of labile PIP - CTC complex, and hence, quantitative complex is formed [18]. Further, CTC volume addition leads to a decrease in the absorbance.

Literature survey shows that the mixed ligand complex (formed between cobalt, thiocyanate, and drug) decomposes at higher $\mathrm{pH}$ values leading to a decrease in absorbance intensity [19]. Hence, in the present study, the effect of variation of $\mathrm{pH}$ of the aqueous phase was studied within the range of 1-4. A maximum absorbance was observed at $\mathrm{pH}$

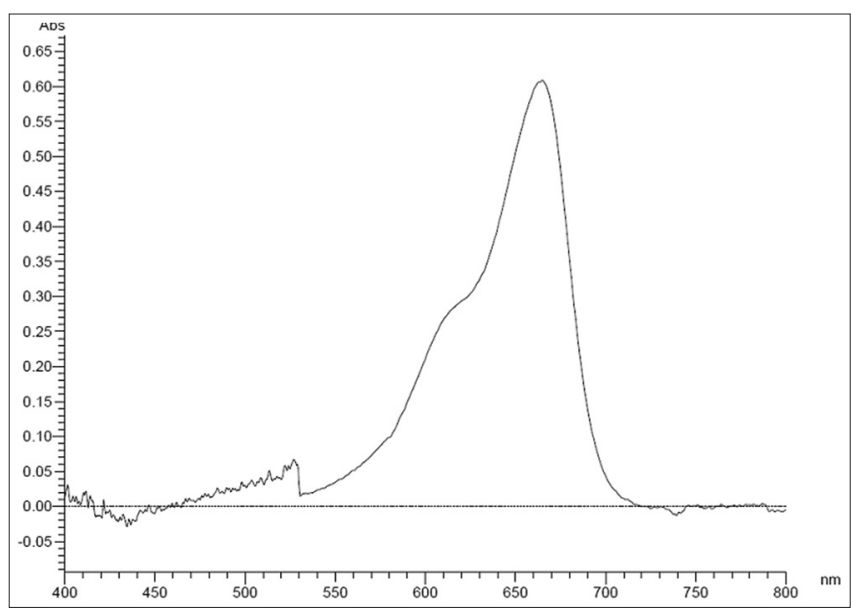

Fig. 2: Visible spectrum of piperacillin - cobalt thiocyanate solution ion pair complex

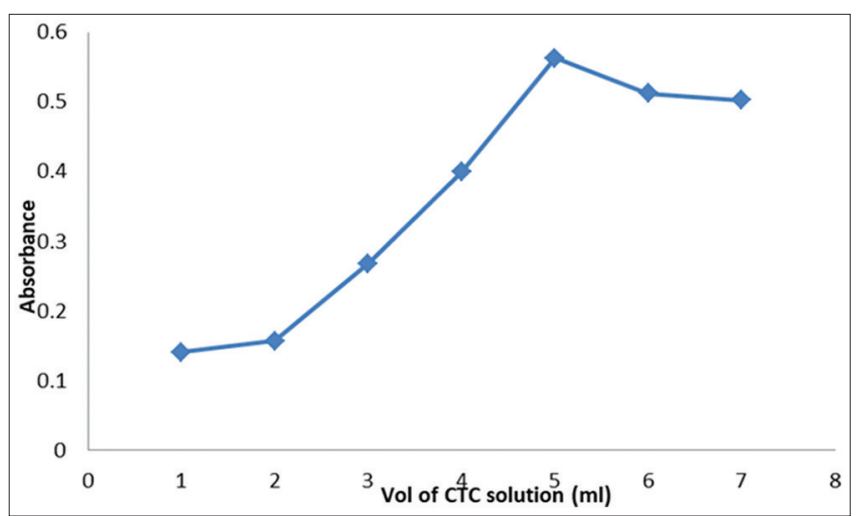

Fig. 3: Effect of volume of cobalt thiocyanate solution value of two (Fig. 4a.), indicating that protonated drug is helping the ion-pair formation and extraction of the formed complex is maximum at this $\mathrm{pH}$. Hence, citrate buffer solution ( $\mathrm{pH}$ 2.0) was selected for further investigation. Formation of a single extractable complex is confirmed from the same $\lambda \max$ and shape of absorption spectra in the studied $\mathrm{pH}$ range. The optimum volume of buffer solution $\left(\mathrm{pH}_{2}\right)$ is found to be $4 \mathrm{~mL}$ (Fig. 4b).

Benzene, chloroform, dichloromethane, nitrobenzene, and aniline were used as extracting solvents for the complex. Nitrobenzene was found to be the most convenient solvent as it gave the best results and the results were stable (Fig. 5). Absorbance values were found to be reproducible with single extraction of ion pair using $10 \mathrm{~mL}$ of nitrobenzene $3: 2$ volume ratio of aqueous to organic phase solvents) and a decreasing trend of absorbance was observed at lower volume ratio of organic phase.

Within the studied range of shaking time ( $30 \mathrm{~s}$ to $3 \mathrm{~min}$ ) of aqueous and organic phases, its influence on absorbance was found to be insignificant, and hence, 1 min shaking time was accepted. In the proposed method, the order of addition of the optimized volumes of reagents is PIP, buffer, CTC, water, and nitrobenzene. Equimolar concentrations of PIP and CTC were used in continuous variation [20] method to establish the composition of the complex, and it indicates the association of two PIP molecules with each CTC. It is also supported by molar ratio method [21]. Accordingly, the chemical reaction involved in the formation of colored complex can be shown as CTC +2 PIP $\rightarrow$ (CTC) (PIP) $)_{2}$. The developed color is found be stable for minimum $24 \mathrm{~h}$ at room temperature.

\section{Chromophore formation and chemistry}

Organic analytes possessing positive charge can be determined using thiocyanate complexes having metal ions such as $\mathrm{Cr}(\mathrm{III}), \mathrm{Fe}(\mathrm{III}), \mathrm{Co}(\mathrm{II})$, and $\mathrm{Zn}(\mathrm{II})$ by different techniques like spectrophotometry, AAS and ion selective electrodes [22]. CTC, a classical reagent is formed by the combination of $\mathrm{NH}_{4} \mathrm{SCN}$ and cobaltous nitrate. It has been demonstrated to be an appreciable reagent for both the qualitative detection and quantitative determination of amino group-containing organic compounds. Hence, CTC is used as a chromogenic reagent in the present case. Presence of secondary and alicyclic tertiary amino groups in PIP is exploited for its estimation by complexing with CTC at $\mathrm{pH} 2$, that is, acidic $\mathrm{pH}$ medium facilities the protonation of $2^{\circ}$ or $3^{\circ}$ amine nitrogen atom of PIP which in turn subsequently participate in the development of bluish-green colored ion pair complex. The formed ternary complex comprises PIP, thiocyanate and cobalt as main ligand and second ligand, and metal ion, respectively, with a ratio of 2:4:1 (Fig. 6). CTC ion is a weak complex and is stabilized to some extent by the development of ion pair with PIP. Thiocyanate is added in higher amounts than stoichiometric requirement for further stabilization of the formed labile ion pair complex. Extraction of ion pair into organic solvent helps for its satisfactory stabilization and eliminates any interference from the unreacted excess amount of thiocyanate complex as it is left behind in aqueous phase [23]. The so-formed ion pair complex in aqueous phase is extractable quantitatively into nitrobenzene, which is determined by visible spectrophotometer at $665 \mathrm{~nm}$. Chances of

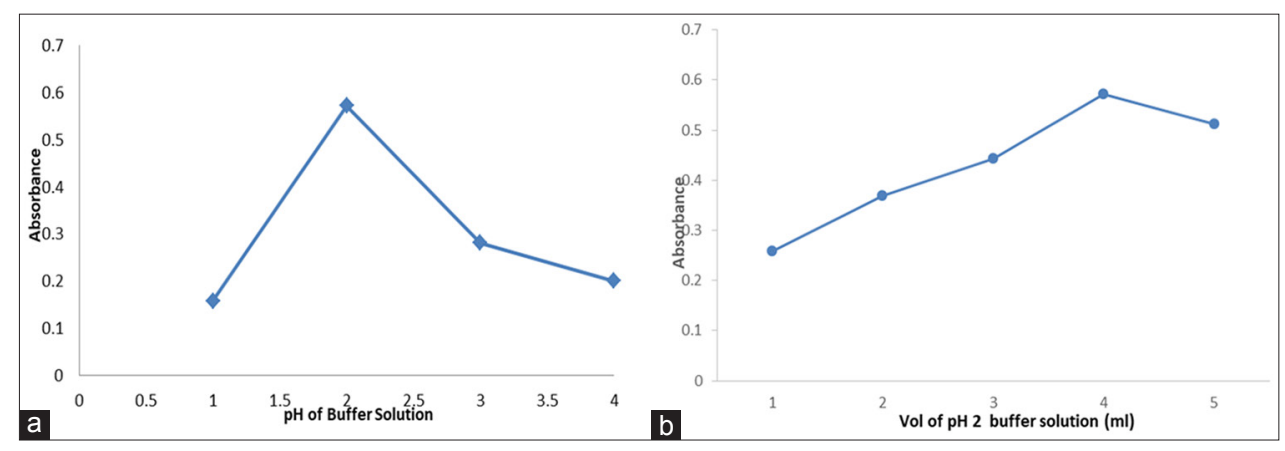

Fig. 4: (a) Effect of pH of buffer solution and (b) effect of volume of buffer (pH 2) solution 
involvement of the coordinate covalent bond between nitrogen atoms of PIP and CTC can be eliminated based on steric hindrances associated with amines present on drug. Moreover, the observed effect of $\mathrm{pH}$ on absorbance of complex and higher absorbance in acidic $\mathrm{pH}$ supports the ion pair formation. Such ion pair formation between protonated nitrogen atom of drug (in acidic pH) and CTC due to electrostatic attraction was reported by earlier researchers $[23,24]$. The entire extraction procedure can be simply represented as $\mathrm{PIP}_{\text {aq }}+\mathrm{CTC}^{-} \rightleftharpoons \mathrm{PIP}^{+}$ $\mathrm{CTC}^{-}{ }_{\mathrm{aq}} \rightleftharpoons \mathrm{PIP}^{+} \mathrm{CTC}^{-}{ }_{\text {org }}$. Subscripts "aq" and "org" represent aqueous and organic phases, respectively. Washing of the nitrobenzene extract with water is avoided because the fragile ion pair complex may decompose by shifting the equilibrium to the right which leads to the discharge of color [18]

\section{Optimized method procedure}

In to a series of $125 \mathrm{~mL}$ separating funnels, aliquots of standard drug solution $(3-18 \mu \mathrm{g} / \mathrm{mL})$ were taken. Then, added $4 \mathrm{~mL}$ of buffer solution and $5 \mathrm{~mL}$ of CTC solution. The volume of each aqueous phase in each separating funnel was adjusted to $15 \mathrm{~mL}$ with distilled water. To each separating funnel, $10 \mathrm{~mL}$ of nitrobenzene was added, and the contents were shaken for $1 \mathrm{~min}$. The two phases were separated and organic layer was collected to dry it over anhydrous sodium sulfate. The absorbance of the organic layer was measured against a similar reagent blank.

\section{Validation of method}

\section{Linearity and range}

The calibration curve was constructed by plotting a graph between absorbance versus concentrations in the range of $3-18 \mu \mathrm{g} / \mathrm{mL}$ and was found to be linear (Fig. 7). A point of the calibration graph indicates the mean value of three independent measurements (Table 1). $y=0.0615 x+0.0213$ was the linear regression equation. The correlation coefficient was $>0.999$, and hence, the linearity of the proposed analytical method was tested. Table 2 represents different optical and regression parameters.

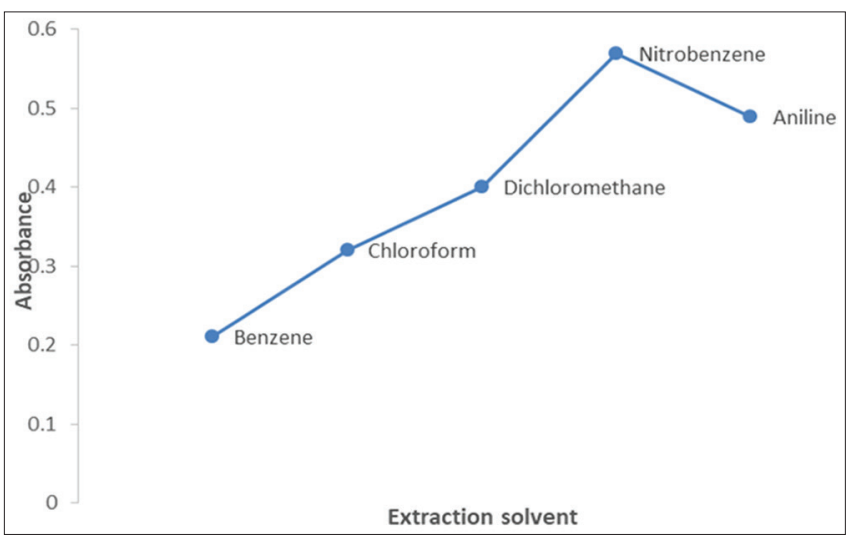

Fig. 5: Effect of solvent nature

\section{Accuracy}

Percent recovery values were determined to know the accuracy of the proposed method. This was performed by adding different amounts $(50 \%, 100 \%$, and $150 \%)$ of bulk samples of PIP to $6 \mu \mathrm{g} / \mathrm{mL}$ to maintain the total amount of drug (theoretical) concentration within the linearity range. The percentage recovery values were in the range of 99.26-99.88 (Table 3). Low values of standard deviation (SD) and relative standard deviation (\%RSD) indicate a high level of accuracy for the proposed method.

\section{Precision}

Three different concentrations of PIP were selected in the linear range $(3-18 \mu \mathrm{g} / \mathrm{mL})$ to study intra- and inter-day precision. Each concentration was analyzed in six independent series on the same day and on 6 consecutive days (Table 4). \% RSD values of intra- and interday studies varied in the range $0.741-1.16$ and $0.71-1.06$, respectively, indicating the satisfactory precision of the method.

\section{Ruggedness}

To evaluate the ruggedness of the proposed developed method, assay of 3,9 , and $18 \mu \mathrm{g} / \mathrm{mL}$ of PIP was carried out under the same optimized conditions on different days by two different analysts. Reproducible

Table 1: Calibration values of PIP

\begin{tabular}{ll}
\hline Concentration $(\boldsymbol{\mu g} / \mathrm{mL})$ & Absorbance* $^{*}$ \\
\hline 3 & 0.206 \\
6 & 0.384 \\
9 & 0.587 \\
12 & 0.753 \\
15 & 0.945 \\
18 & 1.128 \\
\hline
\end{tabular}

${ }^{*}$ Average of three determinations, PIP: Piperacillin

Table 2: Optical characteristics, statistical data of the regression equations, and validation parameters for of PIP

\begin{tabular}{|c|c|c|}
\hline S. No & Parameter & Observation \\
\hline \multicolumn{3}{|c|}{ Optical characteristics } \\
\hline 1. & Apparent molar absorptivity $(\mathrm{L} / \mathrm{mol} / \mathrm{cm})$ & $3.33 \times 10^{4}$ \\
\hline 2. & Sandell's sensitivity $\left(\mu \mathrm{g} \mathrm{cm}^{-2} \mathrm{~A}^{-1}\right)$ & 0.0155 \\
\hline \multicolumn{3}{|c|}{ Regression analysis } \\
\hline 1. & Slope & 0.061 \\
\hline 2. & Intercept & 0.021 \\
\hline 3. & Regression coefficient (r) & 0.9996 \\
\hline \multicolumn{3}{|c|}{ Validation parameters } \\
\hline 1. & $\lambda \max (\mathrm{nm})$ & 665 \\
\hline 2. & Beer's law limit (Linearity, $\mu \mathrm{g} / \mathrm{mL}$ ) & $3-18$ \\
\hline 3. & Limit of detection $(\mu \mathrm{g} / \mathrm{mL})$ & 0.35 \\
\hline 4. & Limit of quantitation $(\mu \mathrm{g} / \mathrm{mL})$ & 1.0 \\
\hline 5 & Stability period (hours) & Minimum 24 \\
\hline
\end{tabular}

PIP: Piperacillin

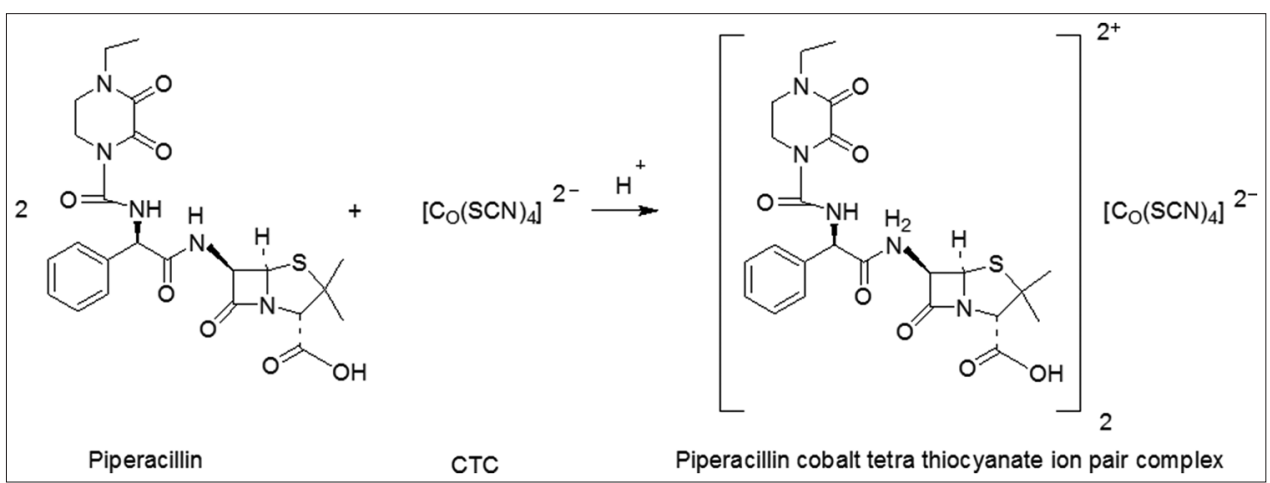

Fig. 6: Formation of ion pair complex 
Table 3: Recovery of PIP

\begin{tabular}{|c|c|c|c|c|c|c|}
\hline $\begin{array}{l}\text { Level of } \\
\text { recovery (\%) }\end{array}$ & $\begin{array}{l}\text { Nominal } \\
\text { concentration used } \\
(\mu \mathrm{g} / \mathrm{mL})(\mathrm{a})\end{array}$ & $\begin{array}{l}\text { Amount of } \\
\text { drug added } \\
(\mu \mathrm{g} / \mathrm{mL})(\mathrm{b})\end{array}$ & $\begin{array}{l}\text { Total amount of } \\
\text { drug }(a+b)(\mu g / m L) \\
\text { (theoretical) }\end{array}$ & $\begin{array}{l}\text { Amount of drug } \\
\text { recovered }(\mu \mathrm{g} / \mathrm{mL}) \\
\text { (practical) }\end{array}$ & $\begin{array}{l}\text { Statistical } \\
\text { evaluation }\end{array}$ & $\begin{array}{l}\text { Percentage } \\
\text { recovery=Practical/ } \\
\text { Theoretical } \times 100\end{array}$ \\
\hline \multirow[t]{3}{*}{50} & 6 & 3 & 9 & 8.99 & Mean:8.97 & 99.88 \\
\hline & 6 & 3 & 9 & 8.97 & SD:0.012 & 99.66 \\
\hline & 6 & 3 & 9 & 8.96 & \%RSD:0.139 & 99.55 \\
\hline \multirow[t]{3}{*}{100} & 6 & 6 & 12 & 11.96 & Mean:11.97 & 99.66 \\
\hline & 6 & 6 & 12 & 11.98 & SD:0.008 & 99.83 \\
\hline & 6 & 6 & 12 & 11.97 & \%RSD:0.068 & 99.75 \\
\hline \multirow[t]{3}{*}{150} & 6 & 9 & 15 & 14.96 & Mean:14.92 & 99.73 \\
\hline & 6 & 9 & 15 & 14.91 & SD:0.029 & 99.40 \\
\hline & 6 & 9 & 15 & 14.89 & \%RSD:0.197 & 99.26 \\
\hline
\end{tabular}

SD: Standard deviation, RSD: Relative standard deviation, PIP: Piperacillin

Table 4: Intra- and inter-day precision readings

\begin{tabular}{llll}
\hline Concentration of PIP $(\mu \mathrm{g} / \mathrm{mL})$ & Concentration* & & \\
\hline & Intra-day $(\mathrm{Mean} \pm \mathrm{SD})(\boldsymbol{\mu g} / \mathbf{m L})$ & \%RSD & Inter-day $(\mathbf{M e a n} \pm$ SD) $(\boldsymbol{\mu g} / \mathbf{m L})$ \\
\cline { 2 - 4 } 3 & $2.97 \pm 0.02$ & 0.71 & $2.95 \pm 0.02$ \\
9 & $9.15 \pm 0.08$ & 0.83 & $9.15 \pm 0.09$ \\
18 & $17.85 \pm 0.21$ & 1.16 & $17.91 \pm 0.19$ \\
\hline
\end{tabular}

*Average of six determinations, SD: Standard deviation, RSD: Relative standard deviation, PIP: Piperacillin

Table 5: Ruggedness data of PIP

\begin{tabular}{lll}
\hline $\begin{array}{l}\text { Test concentration of PIP } \\
\left(\boldsymbol{\mu g} / \mathbf{m L}^{-1}\right)^{*}\end{array}$ & Concentration \\
\cline { 2 - 3 } & Mean \pm SD $(\boldsymbol{\mu g} / \mathbf{m L})$ & \%RSD \\
\hline 3 & $2.92 \pm 0.021$ & 0.72 \\
9 & $9.15 \pm 0.06$ & 0.66 \\
18 & $17.91 \pm 0.14$ & 0.79 \\
\hline
\end{tabular}

* Average of six determinations, PIP: Piperacillin, SD: Standard deviation, RSD: Relative standard deviation

Table 6: Estimation of PIP from its formulation by visible spectrophotometric method

\begin{tabular}{lllll}
\hline $\begin{array}{l}\text { Powder for } \\
\text { injection } \\
\text { formulation }\end{array}$ & $\begin{array}{l}\text { Labeled } \\
\text { Amount (g) }\end{array}$ & $\begin{array}{l}\text { Amount found* } \\
\text { Mean } \pm \text { SD (g) }\end{array}$ & $\begin{array}{l}\text { Percentage } \\
\text { drug } \\
\text { recovered }\end{array}$ & \%RD \\
\hline Pipracil & 2 & $1.984 \pm 0.008$ & 99.185 & 0.393 \\
\hline
\end{tabular}

*Average of three determinations, PIP: Piperacillin, SD: Standard deviation, RSD: Relative standard deviation

results are evident as there was no significant difference between the analysts. Hence, the proposed method is rugged (Table 5).

Detection of Limits of detection and quantification (LOD and LOQ) LOD and LOQ were calculated to determine the sensitivity of the proposed method based on the signal to noise ratio [25]. LOD and LOQ for PIP were calculated from the values of S (slope of the calibration curve) and $\sigma$ (SD of the response) as per the International Council for Harmonization guidelines (2005) [26].

$$
\begin{gathered}
\mathrm{LOD}=3.3 \times \sigma / \mathrm{S}=0.35 \mu \mathrm{g} / \mathrm{mL} \text { and } \\
\mathrm{LOQ}=10 \times \sigma / \mathrm{S}=1.0 \mu \mathrm{g} / \mathrm{mL}
\end{gathered}
$$

\section{Analysis of pharmaceutical formulations}

The active pharmaceutical ingredient (API) present in the PIP powder for injection (Pipracil ${ }^{\circledR}$ ) was extracted using $0.5 \mathrm{M}$ hydrochloric acid solution, suitable volume of diluent water and sonication for $10 \mathrm{~min}$. As the recovery values of the API are good, the proposed method can

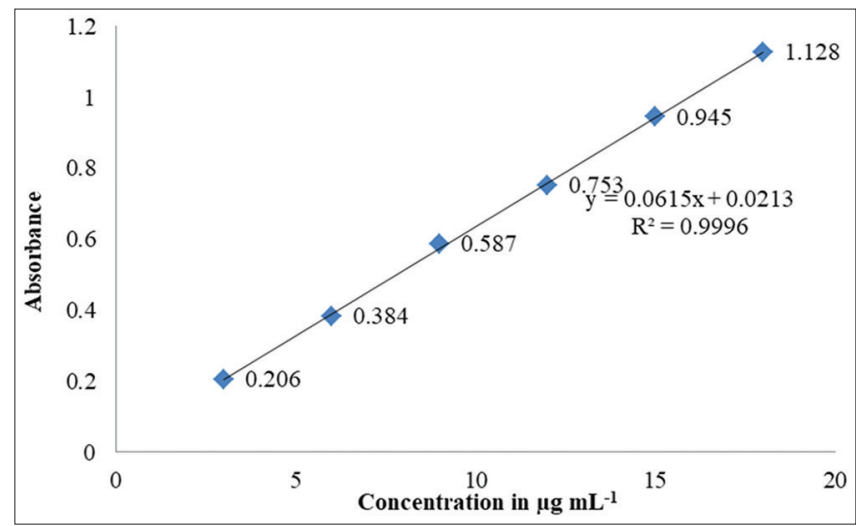

Fig. 7: Calibration graph of piperacillin

be successfully applied to the determination of PIP in pharmaceutical formulations without any interference from common excipients. The amount of API was determined by measuring the absorbance values of chromophores derived from the extracts (Table 6) and using the aboveconstructed calibration curve.

Spectrophotometric method is the generally used method and of choice for routine analysis in industrial quality control (QC) laboratories, especially in developing countries [27-36]. Hence, the present study is an attempt to develop a sensitive visible spectrophotometric method for the determination of PIP in pure and powder for injection formulations using an extractive ion pair complex-forming agent like CTC.

\section{CONCLUSIONS}

A simple visible spectrophotometric method was developed for the quantitative estimation of PIP in pure and powder for injection formulation based on the formation of bluish-green colored ion pair associate with $\left[\mathrm{Co}(\mathrm{SCN})_{4}\right]^{2-}$ followed by its extraction into organic solvent-nitrobenzene. Compared to less polar solvents (benzene, chloroform, dichloromethane, and aniline), nitrobenzene is proved to be a successful extracting solvent in view of higher solubility of ion pair in it. The proposed method is straightforward as there is no need to 
maintain complicated conditions (such as intricate sample treatment and vigilance to maintain critical optimum $\mathrm{pH}$ ) and can be performed without usage of expensive or sophisticated instrumentation. All these advantages help to encourage the proposed method in the routine analysis of PIP (bulk drug and powder for injection formulation) in QC laboratories, as an alternative to the HPLC and LCMS/MS methods.

\section{AUTHORS' CONTRIBUTIONS}

Mr. Giri Prasad Gorumutchu: Experimental work, data collection, and analysis; Prof. Venkata Nadh Ratnakaram: Study design, concept, and manuscript preparation; Dr. Kiran Kumar Katari: Statistical analysis.

\section{CONFLICTS OF INTEREST}

Authors have no conflicts of interest to declare.

\section{REFERENCES}

1. Tan JS, File TM Jr. Antipseudomonal penicillins. Med Clin North Am 1995;79:679-93

2. Hauser AR. Antibiotic Basics for Clinicians. $2^{\text {nd }}$ ed. Philadelphia, PA: Wolters Kluwer; 2013. p. 26-7.

3. Scheer F, Krämer I. A liquid chromatography assay for the simultaneous quantification of piperacillin and ciprofloxacin in human plasma and dialysate in critically III patients undergoing continuous renal replacement therapy. Int J Anal Mass Spectrom Chromatogr 2014; 2:43-51.

4. Barco S, Risso FM, Bruschettini M, Bandettini R, Ramenghi LA, Tripodi G, et al. A validated LC-MS/MS method for the quantification of piperacillin/tazobactamon dried blood spot. Bioanalysis 2014; 6:2795-802.

5. Li Z, Li Q, Yi W, Di C, Chen C. Determination of free and total piperacillin-tazobactam in plasma by HPLC-MS-MS an adapted method for neonates. Chromatographia 2012;75:533-39.

6. Veni PR, Sharmila N, Narayana KJ, Babu BH, Satyanarayana PV. Simultaneous determination of piperacillin and tazobactamin pharmaceutical formulations by RP-HPLC method. J Pharm Res 2013; 7:127-31.

7. Pai PN, Rao GK, Murthy MS, Prathibha H. Simultaneous estimation of piperacillin and tazobactam in injection formulations. Indian J Pharm Sci 2006;68:799-801.

8. Ramalingam P, Rajendran K. Detection of stability and degradation of piperacillin and tazobactam in injectables from in-patient wards and pharmacy by RP-HPLC method. Gulf Med J 2014;3:S132-41.

9. Rao AL, Krishna KS, Ch KK, Raja T. Simultaneous determination of piperacillin and tazobactum in bulk and pharmaceutical dosage forms by RP-HPLC. Int J Pharm J Pharm Sci 2011;3 Suppl 2:1033-40.

10. Augey V, Grosse PY,Albert G, Audran M, Bressolle F. High-performance liquid chromatographic determination of tazobactam and piperacillin in human plasma and urine. J Chromatogr B Biomed Appl 1996; 682:125-36

11. Arzuaga A, Isla A, Gascón AR, Maynar J, Martín A, Solinís MA, et al. Quantitation and stability of piperacillin and tazobactam in plasma and ultrafiltrate from patients undergoing continuous venovenous hemo filtration by HPLC, Biomed Chromatogr 2005;19:570-8.

12. Veillette JJ, Winans SA, Forland SC, Maskiewicz VK. A simple and rapid RP-HPLC method for the simultaneous determination of piperacillin and tazobactam in human plasma. J Pharm Biomed Anal 2016; 131:80-6.

13. Sangeetha S, Kumar M, Kumudhavalli MV, Alexandar S, Jaykar B. Development and validation of UV spectrophotometric area under curve method for quantitative estimation of piperacillin and tazobactam. Int J Chem Tech Res 2017;10:988-94.

14. Toral MI, Nova-Ramirez F, Nacaratte F. Simultaneous determination of piperacillin and tazobactam in the pharmaceutical formulation tazonam by derivative spectrophotometry. J Chil Chem Soc 2012;57:1189-93.

15. Xiaoping B, Yongli BX, Xiaolei W. Content determination of sodium piperacillin and sodium tazobactam for injection by double wavelength UV spectrophotometry. J Chin Pharm Affairs 2003;8:27.

16. Zhang AP, Bai XH, Tong LG. Determination of piperacillin in compound injection by double wavelength ultraviolet spectrophotometry. J Shanxi Med Univ 2004;6:15.

17. Her Majesty's Stationery Office. British Pharmacopoeia. London, UK: Her Majesty's Stationery Office; 1993. p. 77.

18. Amin AS, Aly HM. Utilization of colorimetric and atomic absorption spectrometric determination of aztreonam through ion pair complex formation. Int J Pharm 2000;205:35-41

19. El-Kousy N, Bebawy LI. Determination of some antihistaminic drugs by atomic absorption spectrometry and colorimetric methods. J Pharm Biomed Anal 1999;20:671-9.

20. Job P. Formation and stability of inorganic complexes in solution. Ann Chim 1928;2:113

21. Yoe J, Jones A. Colorimetric determination of iron with disodium-1, 2-dihydroxybenzene-3, 5-disulfonate. Ind Eng Chem Anal Ed 1944;16:111-5

22. Brashy EL, El-Sayed M, Abdallah MF, Sepai EL. Spectrophotometric determination of somefluoroquinoloneantibacterialsbyion-paircomplex formation with cobalt (II) tetrathiocyanate. J Chin Chem Soc 2005; 52:77-84.

23. Abdel-Gawad FM, El-Guindi NM. Spectrophotometric determination of metoclopramide and oxybuprocaine through ion pair formation with thiocyanate and molybdenum (V) or cobalt (II). Anal Lett 1995; 28:1437-47.

24. Fekria M. Determination of amineptine and amprolium hydrochlorides through ion associates with cobalt (II) thiocyanate. Sci Pharm 2017; 70:355-66

25. Sethi PD. HPLC Quantitative Analysis of Pharmaceutical Formulations. India: CBS Publications; 2001.

26. ICHGuidelines. Validation of analytical procedures. TextMethodol2015; 2:8-13.

27. Kiran KK, Nadh RV, Nagoji KEV. Extractive spectrophotometric determination of nicergoline through ion-pair complexation reaction. Orient J Chem 2013;29:263-9.

28. Sudhir MS, Nadh RV. Simple and validated ultraviolet spectrophotometric method for the estimation of febuxostat in bulk and pharmaceutical dosage forms. Orient J Chem 2013;29:1507-14

29. Kiran KK, Nadh RV, Nagoji KE. Determination of bendamustine hydrochloride in pure and dosage forms by ion-associative complex formation reaction. Orient J Chem 2014;30:905-10.

30. Gorumutchu GP, Ratnakaram GV. Oxidative coupling: A tranquil approach for determination of selexipag by visible spectrophotometry. Orient J Chem 2018;34.

31. Gorumutchu GP, Ratnakaram VN. Determination of mianserine using tropaeoline-OOO by ion pair formation. Int J Appl Pharm 2019;1:11.

32. Gorumutchu GP, Ratnakaram VN. Determination of mianserine using Fe3+-phenanthroline by visible spectrophotometry. Res J Pharm Techn 2019;1:12

33. Manasi BK, Anagha MJ. An experimental design approach for optimization of modified colorimetric first-order derivative method for estimation of serralysin in bulk and pharmaceutical formulation. Asian J Pharm Clin Res 2018;11:293-300.

34. Akram M, Monuir ZE, Nora O, Saleem S. Extractive-spectrophotometric determination of some antimuscarinic antagonist in tablet formulations using eriochrome cyanine R. Int J Pharm Pharm Sci 2018:4:22-8.

35. Sharma DK, Singh J, Raj P. Spectrophotometric determination of propranolol hydrochloride and metoprolol tartrate in pharmaceutical dosage forms, spiked water and biological fluids. Int J Pharm Pharm Sci 2018;10:107-15

36. Godambe RD, Disouza JI, Jamkhandi CM, Kumbhar PS. Development of spectrophotometric and fluorometric methods for estimation of darunavir using Qbd approach. Int J Curr Pharm Res 2018;10:13-9. 